\title{
A novel total body digital photography smartphone application designed to detect and monitor skin lesions: A pilot study
}

\author{
Nicholas Guido $^{1}$, Erika L. Hagstrom ${ }^{1}$, Erin Ibler ${ }^{1}$, Chantelle Carneiro ${ }^{1,2}$, Kelsey A. Orrell ${ }^{1}$, Ryan C. \\ Kelm $^{1}$, Alfred W. Rademaker ${ }^{3,4}$, Dennis P. West ${ }^{1,4}$, Beatrice Nardone ${ }^{{ }^{*}}$ \\ ${ }^{1}$ Department of Dermatology, Feinberg School of Medicine, Northwestern University, Chicago, IL \\ ${ }^{2}$ Department of Internal Medicine, Cleveland Clinic, Cleveland, OH \\ ${ }^{3}$ Department of Preventive Medicine, Feinberg School of Medicine, Northwestern University, Chicago, IL \\ ${ }^{4}$ Robert H. Lurie Comprehensive Cancer Center, Northwestern University, Chicago, IL
}

\begin{abstract}
Although some smartphone applications are designed for total body photography (TBP), few offer the specificity that enables self- as well as dermatologist-, detection of new lesions, or change in lesion color or in size as little as $1 \mathrm{~mm}$, on an ongoing basis. The aim of this study is to assess the sensitivity of a novel TBP application in the detection of changes to color and size of simulated skin lesions. Twenty-five subjects underwent one study visit. After baseline photography, new artificial markings were made or naturally occurring pigmented lesions located in any anatomical region were enhanced/ enlarged, and a second matching set of photographs was then taken. From all 25 subjects, a total of 262 skin markings were evaluable. Of these, 241 (92\%) were detected by the app, which resulted in an overall sensitivity of $92 \%$. The high sensitivity establishes the app as capable of providing reliable self-TBP that allows detection and monitoring of new skin lesions or change in both size and color. This method greatly enhances the ability to accomplish ongoing self-monitoring and yet provides quality informing images to the dermatologist to assist in decision-making with the patient.

Clinical Trials registration: ClinicalTrials.gov: NCT02740257, https://clinicaltrials.gov/ct2/show/NCT02740257

Keywords: smartphone application; skin self-examination; skin cancer; total body digital photography; skin lesions

Citation: Guido N, Hagstrom EL, Ibler E, Carneiro C, Orrell KA, et al. A novel total body digital photography smartphone application designed to detect and monitor skin lesions: A pilot study. J Surg Dermatol 2021; 6(2): 177; http://dx.doi. org/10.18282/jsd.v6.i2.177.
\end{abstract}

*Correspondence to: Beatrice Nardone, Department of Dermatology, Feinberg School of Medicine, Northwestern University, 676 N S Clair St, Suite 1600, 60611, Chicago, IL; b-nardone@northwestern.edu

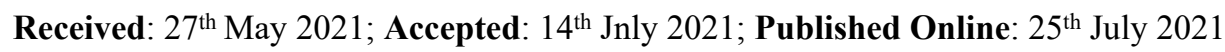

\section{Introduction}

With the emergence of the smartphone and its myriad capabilities less than a decade ago, came the advent of the mobile application market. By 2013, over 200 apps existed that were relevant to dermatology: $18 \%$ of these focused on self-surveillance and diagnosis, and 3.5\% on teledermatology (TD $)^{[1]}$. Several of these apps were designed to allow some differentiation between normal nevi and cutaneous melanoma ${ }^{[1]}$, a growing concern in the U.S. as the incidence rate of melanoma increases ${ }^{[2]}$ while the availability of dermatologists continues to decrease $\mathrm{e}^{[3-5]}$.

Traditionally, TBP is used to globally survey existing lesions and to identify new or changing lesions ${ }^{[6]}$ where the photographer (physician, nurse, or technician) takes an average of 24 photos (range, 4-50) of the patient in various positions. Close-up photos may be taken for selected lesions, and photos are taken at variable intervals for follow-up ${ }^{[7]}$. Moreover, TBP has been reported to help detect early melanoma ${ }^{[8]}$ and TBP combined with skin selfexamination (SSE) increases the sensitivity for detecting new or changed nevi from $60 \%$ to $72 \%$, with increased specificity from $96 \%$ to $98 \%{ }^{[9]}$. Further, patients also are reported to be more compliant with SSE when it is combined with $\mathrm{TBP}^{[0]}$.

A limitation of traditional TBP is that it is a timeconsuming, labor-intensive process since patients must be photographed in a variety of positions to capture the

Copyright (C) 2021 Guido N, et al. This is an Open Access article distributed under the terms of the Creative Commons Attribution-NonCommercial 4.0 International License (http://creativecommons.org/licenses/by-nc/4.0/), permitting all non-commercial use, distribution, and reproduction in any medium, provided the original work is properly cited. 
entire body surface. An advantage of TBP is that it has been shown to be capable of detecting new or subtly changing skin lesions independent of an annual full body skin exam, allowing for better melanoma survival rates related to decreased depth of invasion at time of detection ${ }^{[8,10-12]}$. Limitations with office TBP include the time it takes to train staff, the duration of each photography session beyond normal clinic flow, and the cost of additional photography equipment and/or the photographer ${ }^{[13]}$.

Although currently existing apps allow patients to accomplish TBP from home, there are few specific homebased apps that can detect new lesions or changes to lesions as small as $1 \mathrm{~mm}$ as well as detect changes in color. The aim of this study is to assess the sensitivity of a new and novel home-based TBP app to detect new lesions and/or changes to lesions.

\section{Materials and methods}

A convenience sample of 25 subjects participated in the study that was approved by the Northwestern University Institutional Review Board, and all participants provided written informed consent prior to participation.

Inclusion criteria were 18-85 years of age and selfreported Fitzpatrick skin type I-IV. Exclusion criteria included history of vitiligo or psoriasis (or any active dermatitic condition on the skin surface in the anatomical region to be studied).

The study population underwent one study visit where 2 sets of $\mathrm{iPad} \AA$ photographs were taken by the research team. Each set of images included 3-5 photographs of the relevant anatomic region. After the initial set of photographic images, artificial skin markers were made to either add simulated lesions to the skin of the relevant anatomic region and/or to enhance the subject's naturally- occurring skin lesion (by use of a Sharpie ${ }^{\mathrm{TM}}$ brush tip permanent marker). The choice of permanent skin marker color was black, brown or red. After skin markings were made to each of the 3 anatomical regions, a comparable second set of photographic images was taken in order to determine if the app reliably detected the new marks and/or changes in size and/or color (Figure1).

\section{SkinIO smartphone application}

The app used for the study (SkinIO) is designed to be an enhanced full-body skin scanning system that works on mobile devices and tablets to track changes to skin over time with no additional imaging hardware. SkinIO enables smartphone photography of high-risk patients with 13 photographic poses to accomplish TBP using a mobile device. The images are automatically uploaded to a HIPAAcompliant server environment where they can be rapidly processed to detect most any skin "spot" as small as $1 \mathrm{~mm}$ diameter and of most any color. Dermatologists are enabled to annotate the images and flag specific images for followup at any designated time interval.

SkinIO's proprietary image processing algorithm is comprised of several distinct processes that, either in parallel or in series, form the basis for SkinIO's skin lesion detection engine.

\section{Statistical analyses}

The sensitivity of the app to detect changes in skin marking size and/or color was assessed. Detected new changes were limited by study design to be those placed by use of the variously colored skin markers immediately after the first set of images and immediately before the second set of images. Sensitivity is defined as the rate of app-detected changes compared to the number of artificial skin markings.

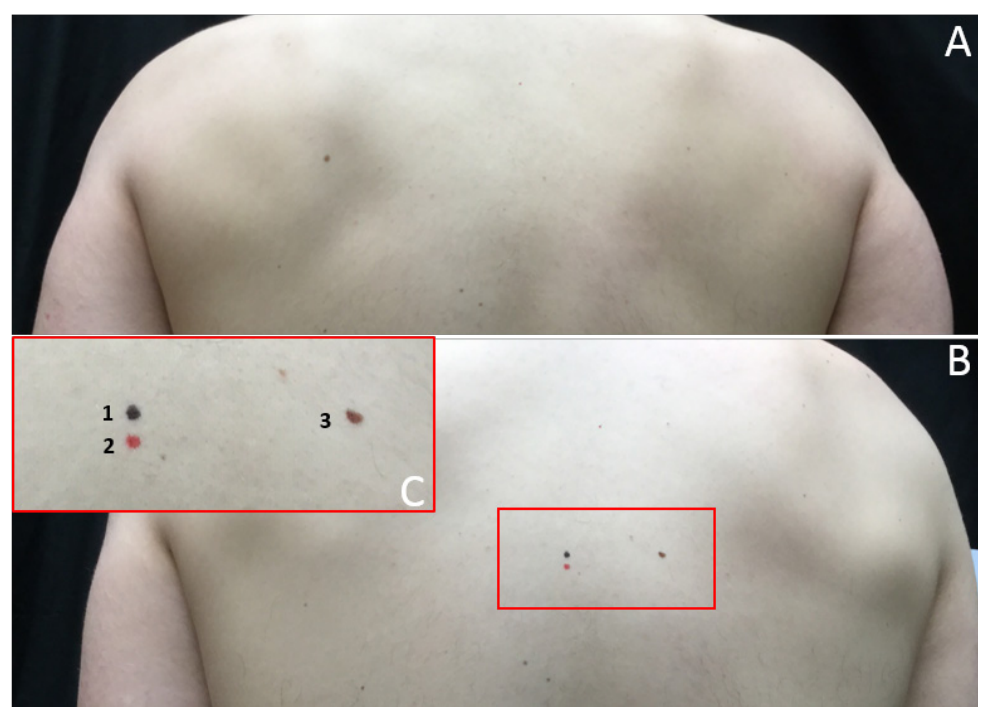

Figure 1. Example of 3 out of 12 artificial markings in subject ID SP016: A) Photos taken with the app before adding artificial skin markings. B) Photos taken after adding artificial skin markings (red rectangle). C) Close-up of artificial skin markings: 1 . Black (Width=2.2 $\mathrm{mm}$; Height $=2.4 \mathrm{~mm}$ ); 2 red (Width=2.1 mm; Height $=2.4 \mathrm{~mm}$ ); 3 brown (Width $1.7 \mathrm{~mm}$; Height=3.0 mm). All 3 artificial skin markings were correctly detected by the app. 
The total number of artificial skin markings made by the researchers versus the total number of skin markings detected by the app informed the determination of app sensitivity.

\section{Results}

A total of 25 subjects were enrolled and completed the study; 25 (Female $=14 /$ Male $=11$; mean age: 28 yo; range 22-55yo; race: Asian $=3$, White: 18, Unknown/Not reported $=4$ ). Of these, 9 subjects were self-reported as Fitzpatrick type II, 12 type III and 4 type IV.

Of these 25 subjects, a total of 269 skin lesions and/ or markings were targeted for study and $262(97 \%)$ were evaluable within the image field. Of the 262 evaluable images, the TBP app detected 241 , resulting in a sensitivity of $92 \%$ (Table 1).

Table 1. Number of artificial skin markings for each subject.

\begin{tabular}{llll}
\hline $\begin{array}{l}\text { Subject } \\
\text { ID }\end{array}$ & $\begin{array}{l}\text { Skin } \\
\text { markings }\end{array}$ & $\begin{array}{l}\text { Skin markings } \\
\text { evaluable within } \\
\text { image field }\end{array}$ & $\begin{array}{l}\text { Skin } \\
\text { markings } \\
\text { detected by } \\
\text { TBP app }\end{array}$ \\
\hline SP001 & 5 & 5 & 4 \\
SP002 & 7 & 7 & 6 \\
SP006 & 9 & 9 & 9 \\
SP007 & 9 & 9 & 8 \\
SP008 & 9 & 9 & 8 \\
SP009 & 10 & 10 & 10 \\
SP010 & 12 & 12 & 11 \\
SP011 & 10 & 10 & 8 \\
SP012 & 13 & 13 & 13 \\
SP013 & 11 & 11 & 12 \\
SP014 & 9 & 9 & 6 \\
SP015 & 11 & 8 & 8 \\
SP016 & 12 & 12 & 11 \\
SP017 & 11 & 11 & 10 \\
SP018 & 11 & 11 & 10 \\
SP019 & 11 & 11 & 6 \\
SP020 & 12 & 11 & 10 \\
SP021 & 13 & 12 & 11 \\
SP022 & 12 & 12 & 12 \\
SP023 & 11 & 11 & 10 \\
SP024 & 13 & 13 & 13 \\
SP025 & 12 & 10 & 10 \\
SP026 & 11 & 11 & 10 \\
SP027 & 13 & 13 & 13 \\
SP028 & 12 & 12 & 241 \\
Total & 269 & 262 & \\
\hline & & & 9 \\
\hline
\end{tabular}

\section{Discussion}

The observed sensitivity in this study indicates that the app as utilized for TBP is both a reliable and convenient approach to monitor and detect changes to skin markings as small as $1 \mathrm{~mm}$ in size and color.

Use of TBP to monitor patients with atypical/dysplastic nevi has been well underway since the late 1980's. By 1992, $41 \%$ of US residency programs reported use of $\mathrm{TBP}^{[14]}$. In $2000,62 \%$ of dermatologists in academic institutions indicated that they use TBP, and in 2010, this increased to $71 \%$ of institutions ${ }^{[15]}$. Rice and colleagues surveyed 49 US dermatology departments in 2010 and found that 33 (67\%) used TBP as a screening method; of those who used TBP, $11(33 \%)$ used digital TBP alone, $11(33 \%)$ used digital with printed images of TBP, and $11(33 \%)$ used printed TBP images alone ${ }^{[13]}$.

Use of TBP images during skin self-examinations (SSEs) has been shown to improve patients' confidence in performing SSEs ${ }^{[9,16]}$ and to increase patients' sensitivity for detection of new or changing skin lesions compared to performance of SSE alone, without access to TBP images ${ }^{[9]}$. In one study, $44 \%$ of melanoma lesions were detected in situ with a small thickness in the group with baseline photography ${ }^{[17]}$. Another study showed that baseline photography aids early detection of melanoma in long-term follow-up of high-risk patients ${ }^{[18]}$. A 5-year prospective observation study of 311 patients in Australia at "extreme high risk" for melanoma demonstrates the complementary effectiveness of TBP, dermoscopy, and sequential digital dermoscopy imaging in the diagnosis of melanoma ${ }^{[19]}$.

Although there have been recent improvements in the treatment of metastatic melanoma, early detection remains one of the most important strategies to reduce mortality. Evidence supporting this approach includes the recent population-based screening efforts, with initial results suggesting a nearly $50 \%$ decrease in melanoma mortality associated with skin cancer screening through total body skin examinations ${ }^{[20]}$. The fact that most melanomas $(\sim 65 \%)$ arise de novo, and are not contiguously associated with a melanocytic nevus, underscores the importance of identifying new lesions in addition to changing lesions to maximize sensitivity for melanoma detection ${ }^{[21]}$.

Smartphone applications targeting skin cancer and melanoma, in particular, have often fallen short after undergoing validation studies, and several have been pulled from the market ${ }^{[22-24]}$. An important issue with apps reliant on automated algorithms has been misdiagnosis of melanoma, and the potential for delay in following up on lesions incorrectly classified as "low risk"[22-24]. Nevertheless, encouraging technological advancements have been made. Applications with mole mapping and photographic imaging have provided dermatologists with visual imagery they can compare over time ${ }^{[25]}$, while smartphone capabilities (cameras, dermoscopy clip-ons, etc.) have provided physicians with the ability to store images and effectively triage referrals ${ }^{[26]}$. The latter is particularly relevant since poor descriptive terms and lack of imaging from referring primary care doctors has 
been reported to lead to delayed follow-up of high risk patients $^{[26]}$.

Teledermatology (TD) has shown promise in this field; it allows digital images with relevant clinical information to be transmitted securely to a consulting dermatologist ${ }^{[27]}$. One TD app was shown to have $98 \%$ sensitivity and $94 \%$ specificity with skin lesion interpretation from photos taken by, and submitted by, patients ${ }^{[24]}$. A recent study evaluated the ability of a mobile smartphone app using novel fractal image analysis to guide diagnosis of pigmented lesions. The app had a sensitivity of $73 \%$ and a specificity of $88 \%$, which was comparable to that observed with clinical diagnostic (sensitivity $88 \%$, specificity $97 \%$ ) $^{[28]}$. However, like many TD apps, it did not require TBP ${ }^{[24]}$. Since melanoma can be located in anatomic regions that are difficult to see or reach, patients are more prone to not photograph such lesions ${ }^{[14]}$.

The SkinIO app is designed to provide patients at high risk for skin cancer with an easy-to-use app that will allow them to monitor skin lesions with built-in notification to the dermatologist for prompt attention to detectable changes in lesions or new lesions that may occur at most any anatomic site.

Multiple factors have worked against widespread adoption of TBP in the monitoring of patients at high risk for melanoma ${ }^{[24]}$. Some dermatologists maintain that TBP is not a helpful tool beyond clinical examination alone, given the scarcity of randomized clinical trials that have evaluated TBP ${ }^{[29]}$. Physicians cite other barriers including the additional time required to perform TBP, difficulties in obtaining reimbursement for TBP, and logistical/ financial constraints, such as the need to obtain software to securely organize and store patient digital images ${ }^{[29]}$. US dermatology residents have reported little emphasis on learning TBP during training, and as many as $67.4 \%$ reportedly prefer additional education ${ }^{[13]}$.

From the patient perspective, TBP is often not covered by third party payors, leading to potentially significant outof-pocket expenses ${ }^{[29]}$. In some geographic regions, there is simply poor access to imaging centers that provide $\mathrm{TBP}^{[29]}$. In addition to the time required to conduct TBP, poor patient acceptance and medical liability issues have been described as barriers to its use ${ }^{[13]}$. The app in this study is designed to circumvent some of these barriers by minimizing the physician and staff time devoted to performing TBP. In our experience, smartphone photography of three anatomic regions was accomplished within 10 minutes. The app design avoids the cost of purchasing hardware.

\section{Conclusions}

Findings from this study inform the feasibility of the app to detect and monitor new skin lesions as well as variation in size and color.

Moreover, these findings support further exploration of the SkinIO app to determine its utility with longitudinal monitoring for detection of naturally-occurring changes to naturally occurring lesions, as well as validation of the methodology for improvement in outcome for patients at high risk for skin cancer. The demonstrated high sensitivity provided by the app for longitudinal skin lesion monitoring represents a technological advance that clearly warrants further exploration.

\section{Funding Source}

Northwestern Memorial Foundation

\section{Conflict of interest}

All the named authors do not have any conflict of interest to disclosure.

This study was approved by the Northwestern University Institutional Review Board (IRB).

\section{References}

1. Brewer AC, Endly DC, Henley J, Amir M, Sampson BP, et al. Mobile applications in dermatology. JAMA Dermatol 2013; 149(11): 1300-1304. doi: 10.1001/jamadermatol.2013.5517.

2. Kohler BA, Sherman RL, Howlader N, Jemal A, Ryerson AB, et al. Annual Report to the Nation on the Status of Cancer, 1975-2011, Featuring Incidence of Breast Cancer Subtypes by Race/Ethnicity, Poverty, and State. J Natl Cancer Inst 2015; 107(6): djv048. doi: 10.1093/jnci/djv048.

3. Suneja T, Smith ED, Chen GJ, Zipperstein KJ, Fleischer AB $\mathrm{Jr}$, et al. Waiting times to see a dermatologist are perceived as too long by dermatologists: Implications for the dermatology workforce. Arch Dermatol 2001; 137(10): 1303-1307. doi:10.1001/archderm.137.10.1303.

4. Tsang MW, Resneck JS Jr. Even patients with changing moles face long dermatology appointment wait-times: A study of simulated patient calls to dermatologists. J Am Acad Dermatol 2006; 55(1): 54-58. doi: 10.1016/j.jaad.2006.04.001.

5. Jacobson CC, Resneck JS, Jr., Kimball AB. Generational differences in practice patterns of dermatologists in the United States: Implications for workforce planning. Arch Dermatol 2004; 140(12): 1477-1482. doi: 10.1001/ archderm.140.12.1477.

6. Hibler BP, Qi Q, Rossi AM. Current state of imaging in dermatology. Semin Cutan Med Surg 2016; 35(1): 2-8. doi: 10.12788/j.sder.2016.001.

7. Dengel LT, Petroni GR, Judge J, Chen D, Acton ST, et al. Total body photography for skin cancer screening. Int J Dermatol 2015; 54(11): 1250-1254. doi: 10.1111/ijd.12593.

8. Feit NE, Dusza SW, Marghoob AA. Melanomas detected with the aid of total cutaneous photography. Br J Dermatol 2004; 150(4): 706-714. doi: 10.1111/j.0007-0963.2004.05892.x.

9. Oliveria SA, Chau D, Christos PJ, Charles CA, Mushlin AI, et al. Diagnostic accuracy of patients in performing skin selfexamination and the impact of photography. Arch Dermatol 2004; 140(1): 57-62. doi: 10.1001/archderm.140.1.57.

10. Barnes LM, Nordlund JJ. The natural history of dysplastic nevi. A case history illustrating their evolution. Arch Dermatol 1987; 123(8): 1059-1061. doi:10.1001/ archderm.1987.01660320101021.

11. Halpern AC, Guerry Dt, Elder DE, Trock B, Synnestvedt M, et al. Natural history of dysplastic nevi. J Am Acad Dermatol 1993; 29(1): 51-57. doi: 10.1016/0190-9622(93)70151-I.

12. Rivers JK, Kopf AW, Vinokur AF, Rigel DS, Friedman $\mathrm{RJ}$,et al. Clinical characteristics of malignant melanomas developing in persons with dysplastic nevi. Cancer 1990; 65(5): 1232-1236.

13. Terushkin V, Oliveria SA, Marghoob AA, Halpern AC. Use of and beliefs about total body photography and dermatoscopy among US dermatology training programs: An update. J 
Am Acad Dermatol 2010; 62(5): 794-803. doi: 10.1016/ j.jaad.2009.09.008.

14. Slue W, Kopf AW, Rivers JK. Total-body photographs of dysplastic nevi. Arch Dermatol 1988; 124(8): 1239-1243. doi:10.1001/archderm.1988.01670080051017.

15. Shriner DL, Wagner RF Jr. Photographic utilization in dermatology clinics in the United States: A survey of university-based dermatology residency programs. J Am Acad Dermatol 1992; 27(4): 565-567. doi: 10.1016/01909622(92)70223-3.

16. Yagerman S, Marghoob A. Melanoma patient self-detection: A review of efficacy of the skin self-examination and patientdirected educational efforts. Expert Rev Anticancer Ther 2013; 13(12): 1423-1431. doi: 10.1586/14737140.2013.856272.

17. Banky JP, Kelly JW, English DR, Yeatman JM, Dowling JP. Incidence of new and changed nevi and melanomas detected using baseline images and dermoscopy in patients at high risk for melanoma. Arch Dermatol 2005; 141(8): 998-1006. doi: 10.1001/archderm.141.8.998.

18. Wang SQ, Kopf AW, Koenig K, Polsky D, Nudel K, et al. Detection of melanomas in patients followed up with total cutaneous examinations, total cutaneous photography, and dermoscopy. J Am Acad Dermatol 2004; 50(1): 15-20. doi: 10.1016/S0190.

19. Moloney FJ, Guitera P, Coates E, Haass NK, Ho K, et al. Detection of primary melanoma in individuals at extreme high risk: A prospective 5-year follow-up study. JAMA Dermatol 2014; 150(8): 819-827. doi: 10.1001/jamadermatol.2014.514.

20. Katalinic A, Waldmann A, Weinstock MA, Geller AC, Eisemann N, et al. Does skin cancer screening save lives?: An observational study comparing trends in melanoma mortality in regions with and without screening. Cancer 2012; 118(21): 5395-5402. doi: 10.1002/cncr.27566.

21. MacKie RM. Clinical recognition of early invasive malignant melanoma. BMJ 1990; 301(6759): 1005-1006.

22. Ferrero NA, Morrell DS, Burkhart CN. Skin scan: A demonstration of the need for FDA regulation of medical apps on iPhone. J Am Acad Dermatol 2013; 68(3): 515-516. doi: 10.1016/j.jaad.2012.10.045

23. Robson Y, Blackford S, Roberts D. Caution in melanoma risk analysis with smartphone application technology. $\mathrm{Br}$ J Dermatol 2012; 167(3): 703-704. doi: 10.1111/j.13652133.2012.11046.x.

24. Wolf JA, Ferris LK. Diagnostic inaccuracy of smartphone applications for melanoma detection--reply. JAMA Dermatol 2013; 149(7): 885. doi: 10.1001/jamadermatol.2013.4337.

25. Lee KB, Weinstock MA, Risica PM. Components of a successful intervention for monthly skin self-examination for early detection of melanoma: The "Check It Out" trial. J Am Acad Dermatol 2008; 58(6): 1006-1012. doi: 10.1016/ j.jaad.2008.03.008.

26. Borve A, Dahlen Gyllencreutz J, Terstappen K, Johansson Backman E, Aldenbratt A, et al. Smartphone teledermoscopy referrals: A novel process for improved triage of skin cancer patients. Acta Derm Venereol 2015; 95(2): 186-190. doi: 10.2340/00015555-1906.

27. Whited JD. Teledermatology research review. Int J Dermatol 2006; 45(3): 220-229. doi: 10.1111/j.1365-4632.2004.02427. $\mathrm{x}$.

28. Maier T, Kulichova D, Schotten K, Astrid R, Ruzicka T, et al. Accuracy of a smartphone application using fractal image analysis of pigmented moles compared to clinical diagnosis and histological result. J Eur Acad Dermatol Venereol 2015; 29(4): 663-667. doi: 10.1111/jdv.12648.

29. Marino ML, Carrera C, Marchetti MA, Marghoob AA. Practice gaps in dermatology: Melanocytic lesions and melanoma. Dermatol Clin 2016; 34(3): 353-362. doi: 10.1016/j.det.2016.03.003. 